\title{
AVALIAÇÃO DE ÁGUA-DE-COCO OBTIDA POR DIFERENTES MÉTODOS DE CONSERVAÇÃO
}

\author{
Evaluation of coconut water obtained by different methods of conservation
}

\author{
Lenise Maria Carvalho Costa ${ }^{1}$, Geraldo Arraes Maia ${ }^{2}$, José Maria Correia da Costa ${ }^{3}$, \\ Raimundo Wilane de Figueiredo ${ }^{4}$, Paulo Henrique Machado de Sousa ${ }^{5}$
}

RESUMO

A cultura do coqueiro vem se expandindo nos últimos anos, e atualmente observa-se uma tendência de aceleração da escala de produção de coco verde para obtenção de água-de-coco. Este acontecimento exige a oferta para o mercado de água de coco de maior estabilidade e vida de prateleira. Dentro deste contexto, objetivou-se com este trabalho comparar a água de coco obtida pelo processo "Hot Fill" em laboratório com outras águas-de-coco comercializadas, submetidas a diferentes métodos de conservação (resfriamento, congelamento, enchimento asséptico e "Hot-Fill”) mediante análises: físico-químicas de pH, acidez titulável, sólidos solúveis, cor, açúcares redutores, açúcares não-redutores; sensoriais de testes de aceitação pelo consumidor com sessenta provadores não treinados, utilizando escala hedônica estruturada de 9 pontos da avaliação global, aparência, sabor, e a escala hedônica de 5 pontos para intenção de compra; e microbiológicas. A comparação entre as amostras da água-de-coco conservadas pelo processo "Hot Fill” experimental com amostras comerciais, conservadas por diferentes métodos de preservação (asséptica, refrigerada, congelada e "Hot Fill") mostrou diferenças nas características físico-químicas e sensoriais. O processamento "Hot Fill" experimental utilizado apresentou qualidade microbiológica satisfatória e boa aceitação sensorial pelos provadores, concluindo-se que a associação do tempo, temperatura e aditivos químicos empregados no processo "Hot Fill" experimental foram adequados para obtenção da água-de-coco com potencial para o mercado e apresentou a maior intenção de compra em relação aos produtos comerciais empregados para comparação.

Termos de indexação: Cocos nucifera L., água-de-coco comercial, enchimento a quente, avaliação sensorial.

\begin{abstract}
The cultivation of green coconut is expanding in the last years and at present it is observed a trend to an increase of the production of green coconut to obtain coconut water. This fact requires an offer to the coconut water market a product with great stability and shelf life. In this context, the purpose of this work was to compare the coconut water obtained by the Hot-Fill process at laboratory to other comercial coconut water subjected to different methods of preservation (cooling, freezing, aseptic filling in cartons and Hot Fill). The comparision between the samples of experimental coconut water preserved by the Hot-Fill process with the comercial samples showed differences in the physical chemicals and sensorial characteristics. The experimental Hot-Fill process used showed satisfactory microbiological quality and good sensorial acceptance by the taste panel, concluding that the association of time, temperature and chemical additives employed in the experimental Hot-Fill process were suitable to obtain coconut water with potential for the marked.
\end{abstract}

Index terms: Cocos nucifera L., commercial coconut water, "Hot-Fill”, sensorial avaluation.

(Recebido para publicação em 22 de novembro de 2004 e aprovado em 6 junho de 2005)

\section{INTRODUÇÃO}

A preocupação com a saúde e a forma física tem-se apoiado também nas bebidas naturais, que visam repor as perdas de água, vitaminas e sais minerais sofridas durante grande esforço físico no trabalho, em esporte e em divertimentos. Dessa forma, existe uma atração dos consumidores por novos produtos e uma tendência por sabores exóticos, naturais, ligados à saúde, a exemplo da água-de-coco (CUENCA et al., 2002).
A água-de-coco é uma bebida natural, pouco calórica, com sabor agradável, conhecida mundialmente e muito apreciada em todo o Brasil, principalmente nas regiões litorâneas. Seu consumo vem crescendo nos últimos tempos, principalmente devido às suas propriedades de reposição de eletrólitos perdidos após uma desidratação ou desgaste físico (ARAGÃO, 2000; AROUCHA \& VIANNI, 2002; PENHA, 1998).

${ }^{1}$ Engenheira de Alimentos, mestre em Tecnologia de Alimentos, do Departamento de Tecnologia de Alimentos/UFC

${ }^{2}$ Engenheiro Agrônomo, PhD em Ciência dos Alimentos, Professor do Departamento de Tecnologia de Alimentos/UFC

${ }^{3}$ Engenheiro Químico, Dr. em Biotecnologia e Ind. de Alimentos, Professor do Departamento de Tecnologia de Alimentos/UFC - Av. Mister Hull, 2977 60356-000 - Fortaleza, CE - correia@ufc.br

${ }^{4}$ Engenheiro Agrônomo, Dr. em Ciência dos Alimentos, Professor do Departamento de Tecnologia de Alimentos/UFC

${ }^{5}$ Químico, mestre em Tecnologia de Alimentos - Departamento de Tecnologia de Alimentos/UFC. 
A água do coco verde pode ser consumida tanto na forma "in natura" quanto processada. Os métodos de processamento empregados visam, essencialmente, inibir a ação enzimática e garantir a estabilidade microbiológica da água-de-coco após a abertura do fruto, mantendo o quanto possível suas características sensoriais originais (ARAGÃO et al., 2001; ROSA \& ABREU, 2002).

Os métodos de conservação podem fazer uso de tratamento térmico com médias e altas temperaturas, adição de aditivos químicos pertencentes ou não a categorias dos conservadores, refrigeração ou congelamento (ROSA \& ABREU, 2002).

Segundo a Instrução Normativa n. ${ }^{0} 39$, de 29 de Maio de 2002, que aprova o regulamento técnico para fixação de identidade e qualidade da água-de-coco, esta pode ser comercializada na forma "in natura", congelada, resfriada, esterilizada, concentrada e desidratada (BRASIL, 2002). Todas as águas comercializadas devem possuir características sensoriais de aspecto, cor, sabor e odor característicos, e estarem dentro dos parâmetros físicoquímicos, com acidez fixa em ácido cítrico $(\mathrm{g} / 100 \mathrm{~mL}), \mathrm{pH}$ com o mínimo de 4,3 , e sólidos solúveis $\left(\mathrm{em}^{\circ} \mathrm{Brix}\right.$ a $20^{\circ} \mathrm{C}$ ) com o máximo de 7,0 (BRASIL, 2002).

Diferentes tecnologias de conservação como congelamento, resfriamento, pasteurização, esterilização, irradiação, tecnologia de métodos combinados, tecnologias de membranas (microfiltração e ultrafiltração) vêm sendo estudadas a fim de inibirem a ação enzimática, garantirem a estabilidade microbiológica da água-de-coco após a abertura do fruto, além de manterem o máximo possível suas características sensoriais e nutricionais (ARAGÃO et al., 2001; CAMPOS et al., 1996; KIKUDA et al., 2002; MALPELLI \& FARIA, 2003; SILVA et al., 2001), com o intuito de fornecer ao consumidor um produto de qualidade e segurança, com maior tempo de armazenamento, praticidade de transporte e armazenamento, favorecendo a comercialização da água de coco verde envasada.

Porém, alguns destes métodos de conservação podem se tornar inviáveis pelo alto custo de instalações industriais ou do armazenamento. E é neste contexto que o processo de enchimento a quente (processo "Hot Fill") pode ser uma alternativa para o problema, pois além do custo do processo não ser tão elevado, o produto pode ser armazenado à temperatura ambiente.

Com este trabalho objetivou-se comparar a águade-coco obtida pelo processo "Hot Fill" com águas-decoco de marcas comerciais preservadas por diferentes métodos de conservação, mediante determinações físicoquímicas, sensoriais e microbiológicas, avaliando o processo como uma opção tecnológica para o aproveitamento industrial do coco verde.

\section{MATERIAIS E MÉTODOS}

A água-de-coco foi processada com a utilização do sistema "hot fill", como será descrito mais adiante, e depois foi avaliada, juntamente com mais quatro águas-de-coco de marcas comerciais, produzidas por diferentes métodos de conservação (refrigeração, congelamento, processamento asséptico e processo "hot fill"), através de análises físico-químicas, microbiológicas e sensoriais. As águas-de-coco comerciais foram adquiridas em supermercados de Fortaleza-CE.

\section{Processamento da água de coco com a utilização do processo "Hot Fill"}

Os frutos dos coqueiros-anões (Cocos nucifera $\mathrm{L}$. cv Verde) com 6-7 meses de idade, adquiridos no mercado atacadista de Fortaleza-CE, foram levados ao Laboratório de Frutos Tropicais do Departamento de Tecnologia de Alimentos - DTA, da Universidade Federal do Ceará UFC, onde foram pré-selecionados e despencados com auxílio de um facão, um pouco antes do início do processamento, evitando-se a retirada do cálice floral. No ato de despencamento foi realizada uma nova seleção retirando-se os excessivamente verdes, gigantes, maduros, rachados e deteriorados.

Em seguida, os cocos foram pré-lavados para remoção de resíduos de sujeira e contaminantes grosseiros, com água potável e submetidos a uma sanificação em tanques de imersão com água clorada (70 ppm de cloro ativo) por 20 minutos, enxaguados com água potável e escorridos para a drenagem total da solução de lavagem.

Depois os cocos foram perfurados com furador em aço inoxidável. Após a abertura, a água-de-coco foi vertida em um recipiente dotado de malha capaz de reter os sólidos ou resíduos provenientes da etapa da abertura.

Realizou-se a padronização/formulação visando uniformizar o pH e a acidez por meio da adição de ácido cítrico, bem como os sólidos solúveis pela adição de frutose e a inibição microbiana e reações de deterioração, através da adição de metabissulfito de sódio, benzoato de sódio e ácido ascórbico. Foi utilizado ácido cítrico monohidratado (VETEC, cód. 237) para promover o abaixamento do $\mathrm{pH}$ até 4,5 e elevar a acidez a $0,11 \mathrm{~g} / 100 \mathrm{~mL}$. Foi utilizada a frutose P.A (VETEC, cód. 374) para padronizar os sólidos solúveis totais em $7{ }^{\circ}$ Brix (BRASIL, 2002), em quantidade não superior a $1 \mathrm{~g} / 100 \mathrm{~mL}$. Foi utilizado o ácido ascórbico P. A.

Ciênc. agrotec., Lavras, v. 29, n. 6, p. 1239-1247, nov./dez., 2005 
(VETEC, cód. 200) com função predominantemente antioxidativa na concentração de $0,13 \mathrm{mg} / 100 \mathrm{~mL}$ (CAMPOS et al., 1996). Como conservantes, o metabissulfito de sódio (VETEC, cód. 222) e o benzoato de sódio (VETEC, cód. 50.408) foram utilizados nas concentrações de $45 \mathrm{mg} / \mathrm{L}$ e $124 \mathrm{mg} / \mathrm{L}$ (CAMPOS et al., 1996), respectivamente.

A água-de-coco foi submetida a tratamento térmico a $90{ }^{\circ} \mathrm{C}$ durante 2 minutos, envasada em garrafas de vidro com capacidade de $200 \mathrm{~mL}$, fechadas hermeticamente e posteriormente resfriadas. O produto devidamente acondicionado foi armazenado à temperatura ambiente $\left(28^{\circ} \mathrm{C}\right)$.

\section{Caracterização físico-química}

As análises físico-químicas nas amostras de águade-coco foram realizadas no Laboratório de Frutos Tropicais / DTA / UFC, localizado em Fortaleza-CE, após 15 dias da sua data de fabricação. Foram realizadas as seguintes análises: $\mathrm{pH}$ - determinado pelo método potenciométrico, utilizando-se um peagâmetro marca QUIMIS, segundo AOAC (1992); acidez titulável pela titulação com hidróxido de sódio e expressa em g de ácido cítrico/100 mL de acordo com as normas analíticas do Instituto Adolfo Lutz (1985); sólidos solúveis totais expressa em ${ }^{\circ}$ Brix, e medida em refratômetro de bancada modelo ABBÉ, conforme as normas analíticas do Instituto Adolfo Lutz (1985); cor - em colorímetro Minolta Color Meter-CR300, expresso como valor L* (Luminosidade variando 0 (preto) a 100 (branco)); açúcares redutores método Lane-Eynon, segundo as normas analíticas do Instituto Adolfo Lutz (1985) e os resultados expressos em termos de percentual de glicose; açúcares não-redutores segundo as normas analíticas do Instituto Adolfo Lutz (1985) e os resultados expressos em termos de percentual de sacarose.

\section{Análises microbiológicas}

As análises microbiológicas da água-de-coco foram realizadas no Laboratório de Microbiologia de Alimentos / DTA / UFC. As análises microbiológicas envolveram a contagem de bactérias aeróbias mesófilas, bolores e leveduras, coliformes a $35^{\circ} \mathrm{C}$, coliformes a $45^{\circ} \mathrm{C}$ e detecção de Salmonella sp.. Essas análises foram realizadas conforme metodologia descrita por APHA (2001) e Silva et al. (2001).

\section{Avaliações sensoriais}

As avaliações sensoriais das amostras de água- de-coco foram realizadas no Laboratório de Análise Sensorial / DTA/ UFC, aplicados a 60 provadores não treinados. Empregou-se teste de aceitação mediante os atributos de avaliação global, aparência e sabor, com utilização de escala hedônica estruturada de 9 pontos, em que o 9 representava a nota máxima, "gostei muitíssimo", e 1 a nota mínima "desgostei muitíssimo" (STONE \& SIDEL, 1993). A intenção de compra do produto também foi verificada, com utilização de escala hedônica de 5 pontos, na qual o 5 representava a nota máxima, "certamente compraria" e 1 a nota mínima, certamente não compraria" (STONE \& SIDEL, 1993).

\section{Análise estatística}

Para efeito de análise estatística das avaliações físico-químicas, utilizou-se um delineamento inteiramente ao acaso com três repetições. Já para análise sensorial o delineamento foi o bloco ao acaso, sendo cada provador considerado um lote. Os resultados físicoquímicos e sensoriais foram tratados estatisticamente mediante a Análise de variância (ANOVA) e aplicado o teste de Tukey entre as médias a 5\% de probabilidade, por meio do programa estatístico Statistical Analisys Sistem (1996).

\section{RESULTADOS E DISCUSSÃO}

\section{Caracterização físico-química}

Na Tabela 1, observa-se os resultados de $\mathrm{pH}$, acidez titulável, sólidos solúveis totais, açúcares redutores e cor das amostras de água-de-coco conservadas por tratamentos diferentes. As amostras de água-de-coco comerciais conservadas pelo processo asséptico e congelamento tiveram seus valores de $\mathrm{pH}$ acima de 4,8 . Esse valor de $\mathrm{pH}$ é susceptível à proliferação de bactérias patogênicas, inclusive Clostridium botulinum, pois o $\mathrm{pH}$ mínimo para multiplicação das cepas varia entre 4,8 e 5,0, segundo Banwart (1989).

Observa-se nos resultados referentes ao $\mathrm{pH}$ que somente as amostras resfriadas e "Hot Fill" experimental não apresentaram diferença significativa a 5\% de probabilidade, o que sugere que provavelmente, as amostras de água-de-coco resfriadas tenham sofrido algum ajuste de $\mathrm{pH}$ como no processo "Hot Fill" experimental. Todas as amostras apresentam-se dentro dos padrões estabelecidos pela Instrução Normativa n. ${ }^{\circ}$ 39, de 29 de Maio de 2002 (BRASIL, 2002), que estabelece pH mínimo de 4,3. 
TABELA 1 - Sólidos solúveis totais (SST), pH, acidez titulável (ATT), açúcares redutores (AR), açúcares não-redutores (ANR) e cor (valor $\mathrm{L}^{*}$ ) de amostras de água-de-coco de diferentes métodos de conservação.

\begin{tabular}{lcccccc}
\hline Amostras & $\mathbf{p H}$ & $\begin{array}{c}\text { ATT } \\
(\mathbf{m g} / \mathbf{1 0 0 g})\end{array}$ & $\begin{array}{c}\text { SST } \\
\left({ }^{\mathbf{0}} \text { Brix }\right)\end{array}$ & $\begin{array}{c}\text { AR } \\
(\% \text { glicose })\end{array}$ & $\begin{array}{c}\text { ANR } \\
(\% \text { sacarose })\end{array}$ & $\begin{array}{c}\text { Cor } \\
\left(\text { valor } \mathbf{L}^{*}\right)\end{array}$ \\
\hline Asséptica & $4,93^{\mathrm{a}}$ & $0,08^{\mathrm{c}}$ & $7,10^{\mathrm{a}}$ & $3,57^{\mathrm{e}}$ & n.e. & $27,99^{\mathrm{a}}$ \\
Resfriada & $4,47^{\mathrm{c}}$ & $0,11^{\mathrm{ab}}$ & $7,00^{\mathrm{a}}$ & $4,97^{\mathrm{d}}$ & n.e. & $28,10^{\mathrm{a}}$ \\
Congelada & $4,89^{\mathrm{b}}$ & $0,06^{\mathrm{d}}$ & $7,30^{\mathrm{b}}$ & $5,15^{\mathrm{c}}$ & n.e. & $28,68^{\mathrm{b}}$ \\
"Hot Fill” comercial & $4,32^{\mathrm{d}}$ & $0,12^{\mathrm{a}}$ & $7,00^{\mathrm{a}}$ & $5,63^{\mathrm{b}}$ & n.e. & $29,84^{\mathrm{c}}$ \\
"Hot Fill” experimental & $4,47^{\mathrm{c}}$ & $0,10^{\mathrm{b}}$ & $7,30^{\mathrm{b}}$ & $6,62^{\mathrm{a}}$ & n.e. & $30,20^{\mathrm{c}}$ \\
\hline
\end{tabular}

Amostras seguidas da mesma letra na mesma coluna não diferem pelo teste de Tukey a 5\%.

n.e.= não encontrado.

A maioria dos valores de acidez titulável das amostras processadas apresentou diferenças significativas a 5\%. As amostras resfriadas e "Hot Fill" comercial apresentaram os maiores valores para acidez $(0,11 \% \mathrm{e}$ $0,12 \%$, respectivamente), enquanto a água-de-coco congelada, o menor $(0,06 \%)$. Os valores de acidez total titulável de todas as amostras encontram-se dentro do limite estabelecido pela Instrução Normativa $\mathrm{n}^{\mathbf{0}} 39$, de 28 de maio de 2002 (BRASIL, 2002), que é entre os valores 0,03 e 0,18 $\mathrm{g}$ de ácido cítrico/100 $\mathrm{mL}$ da amostra.

Os teores de sólidos solúveis totais das amostras mantiveram-se próximos do limite estabelecido pela legislação vigente, que estabelece máximo de 7,0 ${ }^{\circ}$ Brix. Somente as amostras congeladas e "Hot Fill" experimental apresentaram valores maiores que o estabelecido pela legislação, e apresentaram diferença significativa $(\mathrm{p£0} 0,05)$ entre as outras amostras. Estes maiores teores de sólidos solúveis totais para as amostras congeladas e "Hot Fill", provavelmente, estão associados a concentração de solutos para as amostras congeladas, e adição de frutose durante padronização/formulação para as amostra "Hot Fill".

Os teores de açúcares redutores foram bem diversificados em relação ao tratamento utilizado na conservação das águas-de-coco, apresentando diferença significativa de $5 \%$ de probabilidade entre todas as amostras. A amostra asséptica apresentou o menor valor de açúcares redutores, enquanto a "Hot Fill" experimental apresentou o maior, possivelmente, devido a frutose acrescentada durante a padronização do produto.

Não foram encontrados açúcares não-redutores em nenhuma das amostras avaliadas devido, provavelmente, às condições de processamento que favoreceram a hidrólise da sacarose, como adição de ácido cítrico (SNYDER, 1995), bem como o uso de alta temperatura, elevando a concentração de grupos redutores. Silva et al. (2001), avaliando um processo de pasteurização de águade-coco, também não encontrou valores de açúcares nãoredutores na amostra tratada a uma temperatura de $100^{\circ} \mathrm{C}$, durante 10 minutos.

$\mathrm{O}$ valor $\mathrm{L}^{*}$ da amostra congelada apresentou diferença significativa $(\mathrm{p} £ 0,05)$ entre todas as amostras analisadas. Já as amostras asséptica e resfriada apesar de terem sido submetidas a tratamentos térmicos diferentes (esterilização e pasteurização, respectivamente) não apresentaram diferenças entre si a $5 \%$ de probabilidade nos valores de $\mathrm{L}^{*}$. As duas amostras submetidas ao processo "Hot Fill", comercial e experimental, não apresentaram diferença significativa entre si a $5 \%$ de probabilidade e apresentaram os maiores valores de $\mathrm{L}^{*}, \mathrm{o}$ que mostra uma maior estabilização da cor do produto em relação aos demais.

\section{Análises microbiológicas}

As amostras de água-de-coco conservadas pelos diferentes processamentos apresentaram contagens de microrganismos aeróbios mesófilos inferiores a $10 \mathrm{UFC/}$ $\mathrm{mL}$ e bolores e leveduras, inferiores a $10 \mathrm{UFC} / \mathrm{mL}$. As determinações de coliformes totais (Coliformes a $35^{\circ} \mathrm{C}$ ), coliformes termotolerantes (Coliformes a $45^{\circ} \mathrm{C}$ ) apresentaram valores inferiores a $0,3 \mathrm{NMP} / \mathrm{mL}$. A presença de Salmonella sp. não foi detectada nas amostras avaliadas. 
Os resultados encontrados demonstraram qualidade microbiológica satisfatória, evidenciando boas condições higiênico-sanitárias nas diversas etapas do processamento, operações adequadas de limpeza e sanitização dos equipamentos e utensílios. Portanto, o produto final atendeu às normas de higiene estabelecidas pelos órgãos competentes (Ministério da Agricultura e Abastecimento e Agência Nacional de Vigilância Sanitária), que estabelecem os seguintes padrões microbiológicos para a água-de-coco: ausência para coliformes fecais $\left(45^{\circ} \mathrm{C}\right)$ e ausência de Salmonella sp. em $25 \mathrm{~g}$ do produto (BRASIL, 2001, 2002).

\section{Avaliação sensorial}

Na Tabela 2, apresentam-se os resultados do teste de aceitação em laboratório, das amostras de água-decoco comerciais, em comparação à água-de-coco conservada pelo processo "Hot Fill" experimental, tratada a $90^{\circ} \mathrm{C} / 120 \mathrm{~s}$.

Comparando os valores médios para aceitação global, aparência, sabor e intenção de compra, observouse que a água-de-coco conservada pelo processo "Hot Fill" experimental apresentou as maiores médias para todos os atributos avaliados. Verificou-se ainda que a água-de-coco preservada pelo processo "Hot Fill" de marca comercial apresentou os maiores valores de médias juntamente com a "Hot-Fill" experimental, não havendo diferença significativa $(p>0,05)$ entre elas nos atributos aparência e intenção de compra entre os dois processos "Hot Fill".
Já na aceitação global e sabor, foram observadas diferenças significativas $(p \leq 0,05)$ entre as duas amostras "Hot Fill" comercial, sendo que a amostra "Hot Fill" experimental apresentou valor médio 7,0 para a aceitação global, correspondendo ao termo hedônico "gostei moderadamente" e 6,7 para o sabor, ficando entre os termos hedônicos "gostei moderadamente" e "gostei ligeiramente"; enquanto a amostra "Hot Fill" comercial apresentou média 5,8 para a aceitação global, ficando entre os termos "não gostei, nem desgostei e gostei ligeiramente" e para o sabor, média 5,0, correspondente ao termo "não gostei, nem desgostei".

Nas Figuras de 1 a 4, apresentam-se os histogramas de frequiência para os atributos aceitação global, aparência e sabor das notas localizadas na região de aceitação (5 a 9) e para intenção de compra das amostras de água-de-coco comerciais, em comparação à água-de-coco conservada pelo processo "Hot Fill" experimental.

Observa-se uma maior freqüência das notas para os atributos aceitação global (43\%), aparência (97\%) e sabor $(78 \%)$ para as amostras tratadas pelo processo "Hot Fill" experimental; seguida pela amostra "Hot Fill" comercial, com o somatório de $61 \%$ para aceitação global, 93\% para aparência e 55\% para o sabor (Figuras 1 a 3$)$.

No histograma de freqüência para intenção de compra também se observou um maior número de notas localizadas na região de aceitação (notas 3 a 5) para a amostra "Hot Fill" experimental (83\%), seguida pela amostra "Hot Fill" comercial (65\%) (Figura 4).

TABELA 2 - Dados sensoriais de amostras de água de coco-anão verde conservadas pelo processo "Hot Fill" experimental e amostras comerciais conservadas por vários processamentos.

\begin{tabular}{lcccc}
\hline \multicolumn{1}{c}{ Amostras } & Aceitação global & Aparência & Sabor & Intenção de compra \\
\hline Asséptica & $4,4^{\mathrm{c}}$ & $6,4^{\mathrm{c}}$ & $4,2^{\mathrm{bc}}$ & $2,4^{\mathrm{c}}$ \\
Resfriada & $4,9^{\mathrm{bc}}$ & $6,8^{\mathrm{bc}}$ & $4,6^{\mathrm{bc}}$ & $2,6^{\mathrm{bc}}$ \\
Congelada & $4,2^{\mathrm{c}}$ & $6,8^{\mathrm{bc}}$ & $3,8^{\mathrm{c}}$ & $2,3^{\mathrm{c}}$ \\
"Hot Fill” commercial & $5,8^{\mathrm{b}}$ & $7,3^{\mathrm{ab}}$ & $5,0^{\mathrm{b}}$ & $3,2^{\mathrm{ab}}$ \\
"Hot Fill” experimental & $7,0^{\mathrm{a}}$ & $7,7^{\mathrm{a}}$ & $6,7^{\mathrm{a}}$ & $3,7^{\mathrm{a}}$ \\
\hline
\end{tabular}

Amostras seguidas da mesma letra na mesma coluna não diferem pelo teste Tukey no nível de 5\% de probabilidade. 


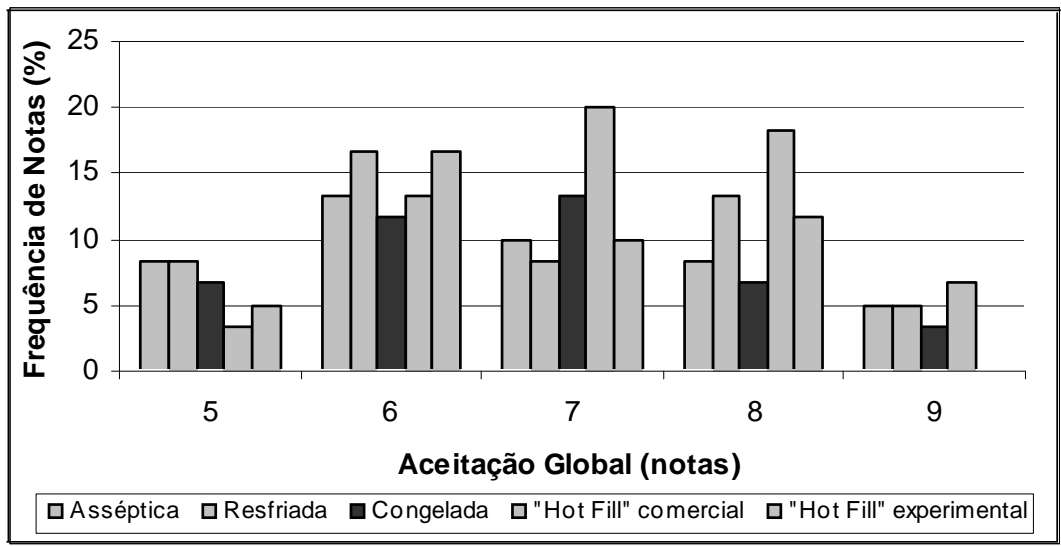

FIGURA 1 - Histograma de frequiência das notas de aceitação global para amostras de água de coco-anão verde conservadas pelo processo "Hot Fill" experimental e amostras comerciais conservadas por vários processamentos.

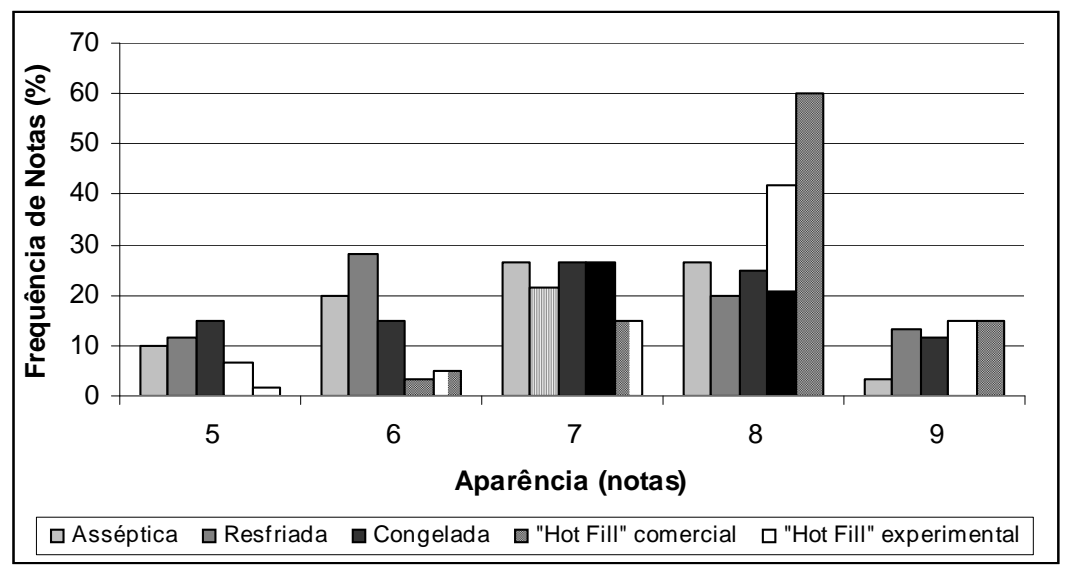

FIGURA 2 - Histograma de frequiência das notas de aparência para amostras de água de coco -anão verde conservadas pelo processo "Hot Fill" experimental e amostras comerciais conservadas por vários processamentos.

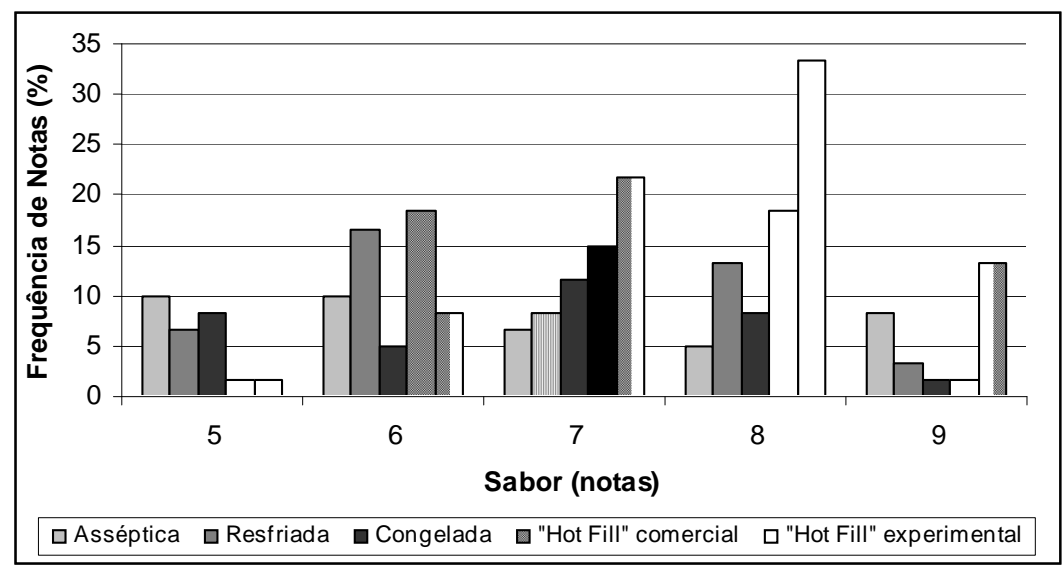

FIGURA 3 - Histograma de frequiência das notas de sabor para amostras de água de coco-anão verde conservadas pelo processo "Hot Fill” experimental e amostras comerciais conservadas por vários processamentos.

Ciênc. agrotec., Lavras, v. 29, n. 6, p. 1239-1247, nov./dez., 2005 


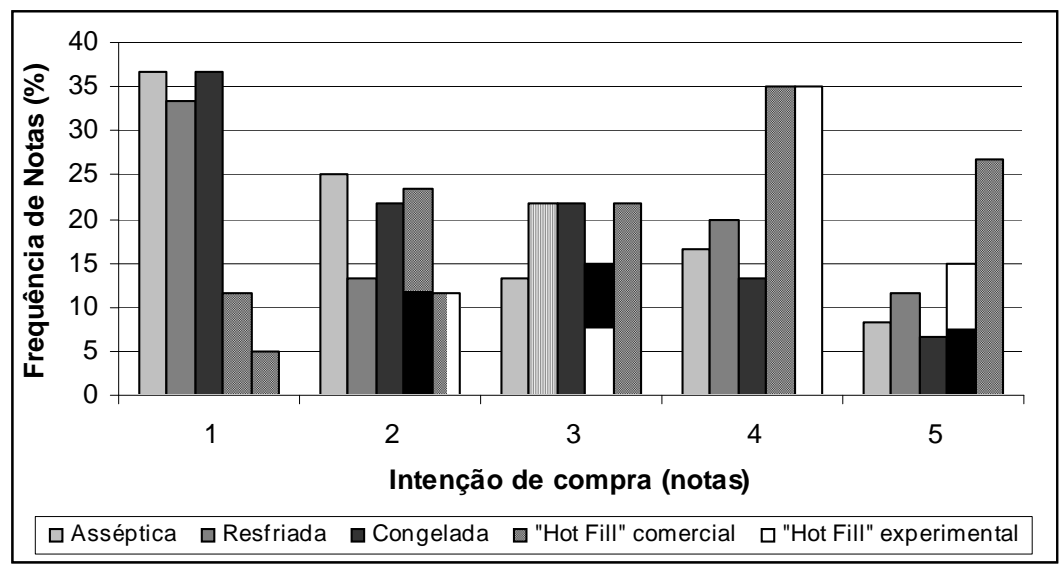

FIGURA 4 - Histograma de freqüência das notas de intenção de compra para amostras de água de coco-anão verde conservadas pelo processo "Hot Fill" experimental e amostras comerciais conservadas por vários processamentos.

Isto sugere diferenças principalmente na formulação dos produtos e processo térmico (tempo e temperatura), indicando que a amostra "Hot Fill" experimental obteve melhor aceitação em todos os parâmetros analisados, quando comparada com a amostra comercial.

Os resultados apresentados na Tabela 2 mostram como o processo pode influenciar na escolha de um determinado produto. A amostra resfriada foi submetida à pasteurização, além da adição de conservantes, antioxidantes e acidulantes, enquanto a amostra asséptica foi submetida à esterilização, adição de frutose para correção dos sólidos solúveis totais ( ${ }^{\circ}$ Brix) e adição de conservante (metabissulfito de sódio). Estes tratamentos provocaram modificações nas características físico-químicas dessas amostras $(\mathrm{pH}$, sólidos solúveis totais, cor e açúcares redutores) que influenciaram os atributos de sabor e aparência e a intenção de compra.

A amostra congelada, apesar de não ter sido submetida a tratamento térmico e nem ter sofrido a adição de aditivos, não apresentou diferença significativa a $5 \%$ de probabilidade em relação aos parâmetros de aceitação global, aparência, sabor e intenção de compra das amostras asséptica e resfriada. Porém, em valor absoluto, a amostra congelada apresentou as menores médias em relação aceitação global, sabor e intenção de compra.

Segundo Fennema (2000), durante o congelamento de soluções aquosas, suspensões celulares ou tecidos, a água da solução é transferidas aos cristais de gelo. Quase todos os constituintes não aquosos são concentrados em uma quantidade decrescente de água não congelada. Devido ao efeito de crioconcentração, a fase congelada sofre significativas modificações em suas propriedades físico-químicas como pH, acidez titulável, força iônica, viscosidade, potêncial de redox, etc, o que pode ter interferido na aceitação dessa amostra.

Já as amostras conservadas pelo processo "Hot Fill" (comercial e experimental), nos mostram que esse é o tratamento de conservação mais indicado para água-decoco, pois o tratamento permitiu manter o $\mathrm{pH}$ e sólidos solúveis totais dentro dos padrões estabelecidos pela legislação. Os parâmetros tempo e temperatura de tratamento $\left(2\right.$ min a $\left.90^{\circ} \mathrm{C}\right)$ utilizados na amostra "Hot Fill" experimental foram adequados para água-de-coco, pois além de inativar enzimas, não provocou escurecimento não enzimático, conforme observado pelas análises de cor.

A redução no $\mathrm{pH}$ e a alta na acidez nas amostras "Hot-Fill" foram compensadas pelo valor de Brix $(7,30)$. Estes resultados contribuíram para as notas apresentadas nos atributos aparência, sabor, avaliação global e intenção de compra.

\section{CONCLUSÕES}

A comparação entre as amostras de água-de-coco conservadas pelo processo "Hot Fill" experimental com amostras comerciais, conservadas por diferentes métodos de preservação (asséptica, refrigerada, congelada e "Hot Fill") mostrou diferenças entre as amostras em suas características físico-químicas e sensoriais. 
Até mesmo as amostras pelo mesmo processo, "Hot Fill" experimental e comercial, apresentaram diferenças, principalmente em seus parâmetros físico-químicos e sensoriais, possivelmente, devido as suas diferentes formulações e processos térmicos empregados.

Todas as amostras de água-de-coco conservadas por outros métodos de preservação (asséptica, refrigerada, congelada e "Hot Fill") apresentaram qualidade microbiológica satisfatória para o consumo humano.

A associação do tempo, temperatura e aditivos químicos empregados no processo "Hot Fill" experimental foram adequados para obtenção da água-de-coco com boa aceitação sensorial.

\section{AGRADECIMENTOS}

Ao Conselho Nacional de Desenvolvimento Científico e Tecnológico - CNPq e a Fundação Cearense de apoio ao Desenvolvimento Científico e Tecnológico FUNCAP pelo apoio financeiro para realização deste trabalho.

\section{REFERÊNCIAS BIBLIOGRÁFICAS}

AMERICAN PUBLIC HEALTH ASSOCIATION. Compendium of methods for the microbiological examination of foods. Washington, 2001. $676 \mathrm{p}$.

ARAGÃO, W. M. A importância do coqueiro anão verde. Aracaju: Embrapa Tubuleiros Costeriros, 2000. Disponível em: <http://www.cpatca.embrapa.br/ 2003.

ARAGÃO, W. M.; ISBERNER, I. V.; CRUZ, E. M. de O. Água de coco. Aracaju: Embrapa Tubuleiros Costeriros, 2001. 32 p. (Documentos, 24).

AROUCHA, E. M. M.; VIANNI, R. Determinação de ácido ascórbico na água de coco por cromatografia líquida e pelo método titulométrico. Revista Ceres, Viçosa, v. 49, n. 283, p. 245-251, 2002.

ASSOCIATION OF OFFICIAL ANALYTICAL CHEMISTS. Official methods of analysis of the Association of Official Analytical Chemistry. 12. ed. Washington, 1992. 1115 p.

BANWART, G. J. Basic food microbiology. 2. ed. New York: V. N. Rheinhold, 1989. p. 101-163.
BRASIL. Instrução Normativa n. 9, 29 de maio de 2002. Aprova o regulamento técnico para fixação de identidade e qualidade da água de coco, constante no Anexo 1.39. Documento do Ministério da Agricultura, Pecuária e Abastecimento. - $\quad$ Disponível - em: Lhtp:wwwagricultura.gov.br/sda/ddiv/pd lin 392002.pdff $>$. Acesso em: 2 dez. 2003.

BRASIL. Resolução RDC n. 12, 2 de janeiro de 2001. Dispõe sobre os princípios gerais para o estabelecimento de critérios e padrões microbiológicos para alimentos. Agência Nacional de Vigilância Sanitária. Disponível em: <http:// www.vigilanciasanitaria.gov.br/anvisa.htmi $/ \bar{x}$. Acesso em: 20 ago. 2001 .

CAMPOS, C. F.; SOUZA, P. E. A.; COELHO, J. V.; GLÓRIA, M. B. A. Chemical composition, enzyme activity and effect of enzyme inactivation on flavor quality of green coconut water. Journal Food Processing Preservation, New York, v. 20, n. 6, p. 487-500, 1996.

CUENCA, M. A. G.; RESENDE, J. M.; SAGGIN JÚNIOR, O. J.; REIS, C. S. Mercado brasileiro do côco: situação atual e perspectivas. In: ARAGÃO, W. M. Côco: pós-colheita. Brasília, DF: Embrapa Informação Tecnológica, 2002. p. 18.

FENNEMA, O. R. Química de los alimentos. 2. ed. Zaragoza: Acribia, 2000. 1258 p.

INSTITUTO ADOLFO LUTZ. Normas analíticas: métodos químicos e físicos para análises de alimentos. 3. ed. São Paulo, 1985. v. 3, 533 p.

KIKUDA, A. T.; TADINI, C. C.; FERNANDES, R. Modelo de primeira ordem multicomponente para inativação térmica em processo descontínuo da peroxidase e polifenoloxidase presentes na água de coco verde (Cocos nucifera $\mathrm{L}$.). In: CONGRESSO BRASILEIRO DE CIÊNCIA E TECNOLOGIA DE ALIMENTOS, 18., 2002, Porto Alegre. Anais... Porto Alegre: SBCTA, 2002. p. 1776.

MALPELLI, D. C.; FARIA, J. A. F. Avaliação da qualidade de água de coco industrializada por pasteurização e enchimento a quente. In: CONGRESSO INTERNO DE INICIAÇÃO CIENTÍFICA DA UNICAMP, 11., 2003, Campinas. Anais... Campinas: Unicamp, 2003. p. T430. 
PENHA, E. M. Características do coco verde para industrialização da água e da polpa gelatinosa. In: CONGRESSO BRASILEIRO DE CIÊNCIA E TECNOLOGIA DE ALIMENTOS, 16., 1998, Rio de Janeiro. Anais... Campinas: SBCTA, 1998. CD-ROM.

ROSA, M. F.; ABREU, F. A. P. Processos convencionais de conservação de água-de-coco. In: ARAGÃO, W. M. Côco: pós-colheita. Brasília, DF: Embrapa Informação Tecnológica, 2002. p. 52-53.

SILVA, C. R. R.; MAIA, G. A.; RODRIGUES, M. C. P.; COSTA, J. M. C.; FIGUEIREDO, R. W.; SILVA, N.;
JUNQUEIRA, V. C. A.; SILVEIRA, N. F. A. Manual de métodos de análise microbiológica de alimentos. 2. ed. São Paulo: Varela, 2001. 229 p.

SNYDER, C. H. The extraordinary chemistry of ordinary. 2. ed. J. Wiley \& Sons, 1995. p. 439-446.

STATISTICAL ANALISYS SYSTEM. Sas Institute Inc. Cary, 1996.

STONE, H.; SIDEL, J. L. Sensory evaluation practices. 2. ed. Florida: Academic, 1993. 338 p. 